\title{
Applying Transtheoretical Model to Promote Physical Activities Among Women
}

\author{
Asiyeh Pirzadeh, ${ }^{1}$ Firoozeh Mostafavi, ${ }^{1, *}$ Fazllolah Ghofranipour, ${ }^{2}$ and Awat Feizi ${ }^{3}$ \\ ${ }_{2}^{1}$ Department of Health Education and Promotion, School of Health, Isfahan University of Medical Sciences, Isfahan, IR Iran \\ ${ }^{2}$ Department of Health Education and Promotion, School of Health, Tarbiat Modares University, Tehran, IR Iran \\ ${ }^{3}$ Department of Mathematics and Epidemiology, School of Health, Isfahan University of Medical Sciences, Isfahan, IR Iran \\ ${ }^{*}$ Corresponding author: Firoozeh Mostafavi, Department of Health Education and Promotion, School of Health, Isfahan University of Medical Sciences, Isfahan, IR Iran. Tel: +98- \\ 3137923244, Fax: +98-3136682509, E-mail:__mostafavi@yahoo.com
}

Received 2014 October 13; Revised 2015 March 7; Accepted: 2015 May 4.

\begin{abstract}
Background: Physical activity is one of the most important indicators of health in communities but different studies conducted in the provinces of Iran showed that inactivity is prevalent, especially among women.

Objectives: Inadequate regular physical activities among women, the importance of education in promoting the physical activities, and lack of studies on the women using transtheoretical model, persuaded us to conduct this study with the aim of determining the application of transtheoretical model in promoting the physical activities among women of Isfahan.

Materials and Methods: This research was a quasi-experimental study which was conducted on 141 women residing in Isfahan, Iran. They were randomly divided into case and control groups. In addition to the demographic information, their physical activities and the constructs of the transtheoretical model (stages of change, processes of change, decisional balance, and self-efficacy) were measured at 3 time points; preintervention, 3 months, and 6 months after intervention. Finally, the obtained data were analyzed through $t$ test and repeated measures ANOVA test using SPSS version 16.

Results: The results showed that education based on the transtheoretical model significantly increased physical activities in 2 aspects of intensive physical activities and walking, in the case group over the time. Also, a high percentage of people have shown progress during the stages of change, the mean of the constructs of processes of change, as well as pros and cons. On the whole, a significant difference was observed over the time in the case group $(\mathrm{P}<0.01)$.

Conclusions: This study showed that interventions based on the transtheoretical model can promote the physical activity behavior among women.
\end{abstract}

Keywords: Exercise, Educational Model, Health Education

\section{Background}

Physical activity is one of the most important indicators of health in communities. A wealth of evidence indicates that regular physical activities reduce the risk of cardiovascular diseases, diabetes, obesity, hypertension, skeletal and joints disorders, and some cancers (colon and breast) (1-5).

Regular physical activities among women bring fitness, balance, and muscular strength $(6,7)$. Also, physical activities have positive effects on the bone density $(8,9)$. Moreover, regular physical activities are effective in reducing body mass index $(10,11)$. In addition to the mentioned advantages, these activities in women provide mental benefits, too (7).

Despite the mentioned advantages, a lot of women exercise no regular physical activities in different countries (12-15). Different studies conducted in the provinces of Iran showed that inactivity is prevalent, especially among women $(15,16)$.
Findings of a national survey among Iranian adults have shown that more than $80 \%$ of the population are physically inactive (17). A review of studies have shown that physical activity is low in Iran $(68.7 \%$ - 70.8\%) (18). Momenan study reported that the prevalence of physical inactivity was $69.8 \%$ and only $30.3 \%$ of women had adequate physical activity (19).

Considering inadequate physical activities in women and their susceptibility to many diseases and other problems caused by the lack of regular physical activities, communities should give priority to solve this problem and education is one of the most effective ways to solve it. Today, the education based on theory or models has priority over traditional interventions, since theories identify the main causes that affect the behavior and changing them can lead to behavior change.

One of the most popular models for studying physical activity behavior is the transtheoretical model or the 
stages of change. The transtheoretical model has emphasized on describing how the attitude changes (20). Determining the time dimension of behavior change, this model can contribute to the classification of people and help them change and maintain their behavior by applying different strategies and processes suitable for each stage. The transtheoretical model has 4 constructs of stages of change, processes of change, self-efficacy, and decisional balance.

Stages of changes include; 1 ) precontemplation: people in the this stage do not intend to take action in the foreseeable future, usually measured as the next 6 months, 2) contemplation: in this stage, people intend to change in the next 6 months, 3) preparation: people now intend to take action in the immediate future, usually measured as 6 months, 4) action: the stage in which people have made specific overt modifications in their lifestyles within the past 6 months, and 5) maintenance: in which people have made specific overt modifications in their lifestyles (21).

Processes of change is the second construct that includes cognitive and behavioral processes (22), self-efficacy (this construct reflects the degree of confidence individuals have in maintaining their desired behavior change) (23) and decision-making balance (pros and cons). When the pros are more than cons, the transformation is happening.

Several experimental studies conducted on women using this model indicate the efficacy of this model in changing the physical activity behaviors. In a study on 150 white women, Bock showed that intervention according to the model of stages of change increased physical activities in the intervention group, 6 months after the intervention (24). Dallow and Anderson also showed that intervention according to the model of stages of change increased physical activities in obese women (25). The study by Opdenacker et al. also indicates that the application of processes in this model have positive effects on the physical activities (26). In the study conducted by Shirazi et al. it is stated that the stages of change model increased physical activities in the intervention group (27). Various studies conducted on the basis of the transtheoretical model on women in different countries with various diseases such as obesity, diabetes, or osteoporosis have shown the effectiveness of the mentioned model. To our knowledge, no studies have been done by applying the transtheoretical model to promote physical activities among women.

\section{Objectives}

Thus, we decided to conduct this study with the aim of determining the application of a transtheoretical model in promoting the physical activities behavior among women residing in Isfahan.

\section{Materials and Methods}

This was a quasi-experimental study conducted on the women from the health centers in Esfahan, Iran. Sample was selected through two-stage cluster sampling. Since, there are two district health centers in Isfahan, 2 city health centers were randomly selected from each district and then the members of control group were randomly selected from one city health center and the members of case group from the other health center.

The sample size (participants) comprised 71 people who were regrouped in the contemplation ( 28 women), preparation (23), and action (20) stages. About 20\% drop out was considered for each group. Inclusion criteria were lack of medical prohibition for physical activities, ability to read and write, married, affected by metabolic syndrome, and take a place in the contemplation, preparation, or action stage for doing physical activities according to the stages of change. The exclusion criteria were unwillingness to participate and medical prohibition for physical activities. After becoming familiar with the objectives of the study, participants completed informed consent forms.

The following questionnaires were also used to collect the data in 3 time points (preintervention, 3 , and 6 months postintervention) in health centers:

International physical activities questionnaire (IPAQshort form), which rated the individual's physical activity during the last 7 day as vigorous, moderate, and walking (28). The 5-point scale questionnaire to determine the stages of change (SECQ) (stages of exercise change questionnaire) was prepared by Marcus et al. It places the individuals in one of the stages of precontemplation, contemplation, preparation, action, and maintenance (29). In this study, the Cronbach $\alpha$ was 0.92 for stages of change.

The people that showed one or more level of progress were referred to "progressive" people; the people who remained in their level were "stable" ones and the individuals with one or more returning back level were placed in the "regressive" group.

Processes of change questionnaire includes cognitive and behavioral items which is rated on a 5-point scale from 0 (never) to 4 (always) (30). Its Cronbach $\alpha$ was 0.91 for this construct. After translation into Persian and then back translation, validity of the questionnaire was confirmed by an expert panel.

The 4-point scale of decisional balance includes the benefits and hindrances of a physical activity and is rated from 0 to 3 (43 items) (31). The reliability of decision-making balance was $\alpha=0.84$.

Also, the self-efficacy questionnaire was used with 16 items which is rated on a 4-point scale ("not quite sure" to "I am quite sure").Zero to 3 scores is given to each item, respectively (32). Its Cronbach $\alpha$ was 0.77 in the present study.

After the questionnaire was completed in preintervension time, the participants were placed in one of the stages (contemplation, preparation, and action). Then, the intervention stage started, by the following activities.

The processes of consciousness raising, dramatic relief, 
and environmental reevaluation were used in the contemplation stage, for the case group. Also, the processes of self-reevaluation and self-liberation were used for the people in the preparation stage. After decision-making balance, the processes of counter conditioning, reinforcement management, stimulus control, and helping relationships were used for the stage of action. The applied processes are described in another article.

Educational sessions for physical activities were held by expert trainers, as follows: First session was allocated to introduce physical activities pyramid (with educational slides) that included endurance and strength training, active and aerobic exercises, and daily activities (walking), lasting 45 minutes. In the second session, the endurance exercises, strength training, balancing, and static contraction were taught in the gathering hall of the health center for 60 minutes. In the third session, the above exercises together with warming-up exercises were done in a park by a trainer and cooperation of the participants and the way of cooling down was instructed at the end for 60 minutes. The correct way of walking and respiration were instructed in the fourth session by the trainer. Finally, the CDs consisting of exercises at home were given to the participants.

To develop self-efficacy, in addition to breaking the sporting behavior into different stages, the women were asked to do the activities step-by-step together with female trainers. Also, verbal encouragement was used to persuade the participants. Moreover, a 60-minute session was held for stress reductions and relaxation.

Three and 6 months after intervention, the question- naires were completed again by the case and control groups. Finally, the data from all 3 stages were analyzed by SPSS software. The repeated measures ANOVA test was used to compare the variables of the stages of change in each group. To compare the other variables (processes of change, self-efficacy, and decisional balance), in each group, Mann-Whitney test was used. The t-test was used to compare the changes between two groups. A 2-tailed $P$ value lower than 0.05 was considered statistically significant.

\section{Results}

The Chi-square test showed no significant differences in the age distribution of the two groups. In the case group, 2 persons (2.8\%) were in the age group of 30 - 40 years; 20 (28\%) were in the age group of 40 - 50 years and 49 (69\%) were in the age group 50 - 60 years. In the control group, 5 (7\%), $22(31 \%)$, and $44(62 \%)$ women were within the age groups of $30-40,40-50$, and $50-60$ years, respectively.

Regarding the education, in case and control group, 53 (74\%) and 57 (80\%) persons were without a high school diploma, respectively and the rest had a high school diploma. Chi-square test showed no significant differences between the two groups $(\mathrm{P}=0.422)$.

Before the intervention, the people stages were as follows: 28 people in the contemplation stage, 23 people in the preparation stage, and 20 people in the action stage. The changes in both groups are shown in Table 1 . The numbers of progressive, stable, and regressive participants are presented in this Table too.

Table 1. The Mean and Standard Deviation of Transtheoretical Constructs at Preintervension, 3 Months, and 6 Months After Intervention in Case and Control Groups ${ }^{\mathrm{a}}$

\begin{tabular}{|c|c|c|c|c|}
\hline Transtheoretical Construct & Before Intervention & $\begin{array}{l}\text { Three Months After } \\
\text { Intervention }\end{array}$ & $\begin{array}{l}\text { Six Months After } \\
\text { Intervention }\end{array}$ & PValue \\
\hline \multicolumn{5}{|l|}{ Cons } \\
\hline Case Group & $18.20 \pm 5.25$ & $15.27 \pm 5.21$ & $12.75 \pm 4.65$ & .002 \\
\hline Control Group & $15.50 \pm 4.07$ & $13.49 \pm 4.75$ & $15.83 \pm 6.05$ & .072 \\
\hline T test & 0.215 & 0.112 & 0.000 & \\
\hline \multicolumn{5}{|l|}{ Pros } \\
\hline Case Group & $44.08 \pm 11.00$ & $52.20 \pm 13.52$ & $54.28 \pm 9.99$ & .000 \\
\hline Control Group & $41.66 \pm 9.89$ & $44.95 \pm 13.58$ & $12.55 \pm 42.83$ & .085 \\
\hline T test & 0.185 & 0.001 & 0.000 & \\
\hline \multicolumn{5}{|l|}{ Self-efficacy } \\
\hline Case Group & $7.84 \pm 4.13$ & $13.60 \pm 9.25$ & $20.75 \pm 9.88$ & .001 \\
\hline Control Group & $6.77 \pm 5.63$ & $7.00 \pm 5.59$ & $8.14 \pm 3.87$ & .676 \\
\hline T test & 0.199 & 0.000 & 0.000 & \\
\hline \multicolumn{5}{|l|}{ Processes of change } \\
\hline Case Group & $47.24 \pm 22.41$ & $52.32 \pm 31.09$ & $69.01 \pm 26.00$ & .002 \\
\hline Control Group & $41.05 \pm 16.65$ & $39.07 \pm 26.79$ & $26.53 \pm 14.23$ & .000 \\
\hline T test & 0.064 & 0.007 & 0.000 & \\
\hline
\end{tabular}

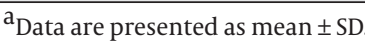


Pirzadeh A et al.

\begin{tabular}{|c|c|c|c|c|c|c|}
\hline \multirow[t]{2}{*}{ Stages of Change } & \multicolumn{3}{|c|}{3 Months After intervention } & \multicolumn{3}{|c|}{6 Months After Intervention } \\
\hline & Progressive & Stable & Regressive & Progressive & Stable & Regressive \\
\hline \multicolumn{7}{|l|}{ Case group } \\
\hline Contemplation & $25(89.29)$ & $3(10.71)$ & 0 & $4(14.28)$ & $21(75)$ & $3(10.71)$ \\
\hline Preparation & $15(65.21)$ & $5(21.74)$ & $3(13.04)$ & $2(8.69)$ & $20(86.96)$ & $1(4.35)$ \\
\hline Action & 0 & $20(100)$ & 0 & 0 & $17(95)$ & $3(15)$ \\
\hline \multicolumn{7}{|l|}{ Control group } \\
\hline Contemplation & 0 & $28(100)$ & 0 & $1(3.57)$ & $24(85.71)$ & $3(10.71)$ \\
\hline Preparation & 0 & $15(65.22)$ & $8(34.78)$ & 0 & $14(60.87)$ & $9(39.13)$ \\
\hline Action & $10(50)$ & & 0 & $8(40)$ & $10(50)$ & 0 \\
\hline
\end{tabular}

${ }^{\mathrm{a}}$ Data are presented as frequency (percent).

Table 3. The Mean and Standard Deviation of Physical Activity Duration (in Minutes) in Preintervention, 3 Months, and 6 Months After Intervention in Case and Control groups

\begin{tabular}{|c|c|c|c|c|}
\hline Physical Activity & Before Intervention & 3 Months After Intervention & 6 Months After Intervention & P-Value \\
\hline \multicolumn{5}{|l|}{ Intense } \\
\hline Case & $17.75 \pm 34.85$ & $65.20 \pm 67.17$ & $69.21 \pm 74.00$ & .000 \\
\hline Control group & $17.39 \pm 34.09$ & $15.58 \pm 45.84$ & $12.18 \pm 32.18$ & .434 \\
\hline Pvalue & .954 & .000 & .000 & \\
\hline \multicolumn{5}{|l|}{ Moderate } \\
\hline Case & $7.46 \pm 18.35$ & $6.96 \pm 14.23$ & $12.31 \pm 19.88$ & .131 \\
\hline Control group & $4.79 \pm 11.72$ & $3.04 \pm 6.36$ & $3.09 \pm 12.60$ & .160 \\
\hline Pvalue & .306 & .009 & .001 & \\
\hline \multicolumn{5}{|l|}{ Walking } \\
\hline Case & $16.41 \pm 36.23$ & $60.20 \pm 13.52$ & $79.94 \pm 95.23$ & .000 \\
\hline Control group & $13.80 \pm 27.69$ & $13.85 \pm 27.58$ & $12.73 \pm 36.03$ & .882 \\
\hline Pvalue & .631 & .000 & .000 & \\
\hline
\end{tabular}

Table 2 shows the mean of constructs processes of change, self-efficacy, and pros and cons during 3 periods of preintervention, 3 months, and 6 months after intervention. Repeated measure ANOVA has shown that processes of change, self-efficacy, and the pros and cons have significant changes $(\mathrm{P}<0.001)$.

The $t$ test showed that intense and intermediate activities and walking had no significant differences in both groups (case and control) before the intervention. However, a significant increase is seen after intervention in the case group, in the two categories of intense activities and walking. Table 3 shows the relevant data in this regard.

\section{Discussion}

This study was conducted to evaluate the application of transtheoretical model in promoting the physical activities behavior. This study was conducted on 142 women with metabolic syndrome without loss of participants. After 3 months from intervention, $89.29 \%$ and $65.21 \%$ of the case group had shown progress in the contemplation and preparation stages, respectively. These rates were $14.28 \%$ and $8.69 \%, 6$ months after the intervention. These changes caused by interventions based on the transtheoretical model and using processes of change. The progress during the stages of change could also be seen in other studies such as Titze et al., Lach et al. and Woods et al. (33-35). The progress in the stages of change is possible by using different processes of change. As it can be seen in the present study, the processes of change showed significant increase, 3 and 6 months after the intervention as compared to preintervention period $(\mathrm{P}<0.001)$. This increase was due to the training interventions by using the processes. Studies done by Dallow, Anderson, and Kirk et al. have also shown that the processes of change have increased after a period of time $(25,36)$.

On the other hand, one of the effective factors in doing physical activities is self-efficacy, which increased over time in the case group. Manely and Nishida have also emphasized the effectiveness of self-efficacy in the behavioral changes. Their studies indicate that the people with 
higher self-efficacy do better and significantly in their physical activities $(37,38)$.

These results agree with results of Dallow study, in which the efficacy has increased in women after the intervention. Likewise, In Pan study, self-efficacy has increased in case group after intervention. Effect of intervention on increasing self-efficacy is evident (25).

Increase in self-efficacy needs intervention, as the Callaghan study, which was conducted prospectively showed a slight increase in self-efficacy (39).

Because the study was conducted step-by-step with female trainers and encouragement, intervention was effective. In addition, the use of effective strategies to increase self-efficacy has been recommended in several studies (40).

After the intervention in the case group, the pros also had significant increase $(\mathrm{P}<0.001)$. The role of pros could not be ignored. Various studies have shown direct or indirect roles of pros on physical activities $(38,40,41)$.

Reducing the cons is another effective factor in the physical activities and progression in stages of change. This change has been observed for the case group, in the present research $(\mathrm{P}<0.001)$. It is stated in Gorely's study that reducing cons moves the people from the contemplation to the action stage (42). According to Kim, the cons had its effective role in self-efficacy (43). In the study by Pan on students and the study by Taymouri on young adults, the cons had no direct effects on physical activities $(44,45)$. However, decisional balance is an important aspect and the balance between the pros and cons could make the individuals to have physical activities.

The mean duration of intense physical activities has shown significant increase in this study. In the case group after 3 and 6 months of intervention, it reached to 69 minutes $(\mathrm{P}<0.001)$. The mean duration of moderate physical activities has increased too, but its change was not significant $(\mathrm{P}=0.131)$.

After 3 months, walking time has reached from $16.41 \mathrm{~min}$ utes to 60.20 minutes and to 79.94 minutes after 6 months, in case group, showing a significant increase $(\mathrm{P}<0.001)$.

Since the world health organization has announced that people should have a minimum of 75 minutes intense physical activities, or 150 minutes of moderate physical activities or a combination of both (46), it seems that we could make the physical activities in the case group to the required minimum rate. It indicates the effects of training-based transtheoretical model. Increasing the physical activities has been approved by various studies by the use of the transtheoretical model $(26,27,36,37)$.

This study had several limitations. First, given the level of female literacy, questionnaires were very time-consuming and beyond the scope of participants. Physical activity questionnaires were self-administered that seemed to cause a bias in the results. So, it is recommended using a pedometer for future studies. Finally, generalizability of our results to the whole women from the sample of women attending health centers is not possible.
This study showed that in addition to having effects on the progress of individuals during the stages of change, education based on transtheoretical model has promoted the regular physical activity behavior among the women of Isfahan using the processes of change, increasing the pros and self-efficacy and even decreasing the perceived cons.

\section{Acknowledgments}

This study was granted by Isfahan university of medical sciences, Isfahan, Iran. It was based on a PhD degree thesis approved in the school of health, Isfahan university of medical sciences (Project No: 392283).

\section{Footnotes}

Authors' Contribution:Asiyeh Pirzadeh, Firoozeh Mostafavi, Fazllolah Ghofranipour, Awat Feizi conceived and designed the evaluation and drafted the manuscript. Asiyeh Pirzadeh collected the clinical data, interpreted them and revised the manuscript. Awat Feizi participated in performing parts of the statistical analyses. Firoozeh Mostafavi reanalyzed the clinical and statistical data and revised the manuscript. All authors read and approved the final manuscript.

Conflict of Interest:None declared.

\section{References}

1. Bouchard C, Malina RM, Pérusse L. Genetics of fitness and physical performance.New Yprk: Human Kinetics; 1997.

2. Warburton DER, Nicol CW, Bredin SS. Health benefits of physical activity: The evidence. Can Med Assoc J. 2006;174(6):801-9.

3. Taylor RS, Brown A, Ebrahim S, Jolliffe J, Noorani H, Rees K, et al. Exercise-based rehabilitation for patients with coronary heart disease: systematic review and meta-analysis of randomized controlled trials. Am J Med.2004;116(10):682-92. doi: 10.1016/j.amjmed.2004.01.009. [PubMed:15121495]

4. Warburton DE, Glendhill N, Quinney A. The effects of changes in musculoskeletal fitness on health. Can J Appl Physiol. 2001;26(2):161-216. [PubMed: 11312416]

5. Lee IM, Skerrett PJ. Physical activity and all-cause mortality: What is the dose-response relation? Med Sci Sports Exerc. 2001;33(6 Suppl):S459-71. [PubMed: 11427772]

6. Yavarian Y, Nikakhtar M. Effect of Aerobicise, on women menta health. J Urmia Nurs Midwifery Fac. 2011;9(1):49-52.

7. Taylor AH, Cable NT, Faulkner G, Hillsdon M, Narici M, Van Der Bij AK. Physical activity and older adults: A review of health benefits and the effectiveness of interventions.J Sports Sci. 2004;22(8):70325. doi:10.1080/02640410410001712421. [PubMed:15370483]

8. Habibzadeh S, Rahmaninia F, Daneshmandi H. Effect of walking program on bone mass density, body composition and some of blood factors in obese and thin girls. Trauma Monthly. 2010;2010(1, Spring):55-9.

9. Garrett NA, Brasure M, Schmitz KH, Schultz MM, Huber MR Physical inactivity: Direct cost to a health plan. Am J Prevent Med. 2004;27(4):304-9.

10. Ghodousi K, Azizi F, Ameli J. Role of physical activity on serum lipids. Kowsar Med J. 2005;10(1):59-64.

11. Sardar MA, Sohrabi M, Shamsian A, Aminzadeh R. Effects of aerobic exercise training on the mental and physical health and social functioning of patients with Type 2 diabetes mellitus. Iran J Endocrinol Metabol. 2009;11(3):251-6.

12. Del Duca GF, Nahas MV, Garcia LM, Mota J, Hallal PC, Peres MA Prevalence and sociodemographic correlates of all domains of 
physical activity in Brazilian adults. Prev Med. 2013;56(2):99-102. doi: 10.1016/j.ypmed.2012.11.007. [PubMed: 23200875]

13. Trost SG, Owen N, Bauman AE, Sallis JF, Brown W. Correlates of adults??? participation in physical activity: Review and update. Med Sci Sports Exerc. 2002;34(12):1996-2001. doi: 10.1097/00005768-200212000-00020.

14. Wilbur J, Miller AM, Montgomery A, Chandler P. Women's physical activity patterns: Nursing implications. J Obstet Gynecol Neonatal Nurs. 1998;27(4):383-92. [PubMed: 9684201]

15. Forghani B, Kasaeyan N, Faghih Imani B, Hossein Pour M, Amini $M$. The assessment of physical activity in non-insulin dependent diabetic women reffered to Endocrine \& Metabolism Research Center. Iran J Endocrinol Metabol. 2000;2(3):169-73.

16. Sadrbafoghi SM, Salari M, Rafiee M, Namayandeh SM, Abdoli AM, Karimi M. Prevalence and criteria of metabolic syndrome in an urban population: Yazd Healthy Heart Project. Tehran Univ Med J. 2006; 64(10):90-6.

17. Sheykh AR, Mohamad A, Mohammad K, Vaseghi S. Non communicable disease risk factors in Iran. Asia Pac J Clin Nutr. 2004;13(3)

18. Maddah M. The factors associated with adult obesity in Iran: a review. Iran J Nutr Sci Food Technol. 2012;7(1):119-27.

19. Momenan AA, Delshad M, Mirmiran P, Ghanbarian A, Azizi F. Leisure time physical activity and its determinants among adults in Tehran: Tehran lipid and glucose study. Int J Prev Med. 2011;2(4):243-51. [PubMed: 22174964]

20. Glanz K, Rimer BK, Viswanath K. Health behavior and health education: theory, research, and practice.New York: John Wiley \& Sons; 2008.

21. Marcus BH, Selby VC, Niaura RS, Rossi JS. Self-efficacy and the stages of exercise behavior change. Res Q Exerc Sport. 1992;63(1):60-6. doi: 10.1080/02701367.1992.10607557. [PubMed:1574662]

22. Prochaska JO, DiClemente CC, Norcross JC. In search of how people change. Applications to addictive behaviors. Am Psychol. 1992;47(9):1102-14. [PubMed:1329589]

23. Bandura A. Self-efficacy: Toward a unifying theory of behavioral change. Psychol Rev. 1977;84(2):191-215. [PubMed: 847061]

24. Bock BC, Marcus BH, Pinto BM, Forsyth LH. Maintenance of physical activity following an individualized motivationally tailored intervention. Ann Behav Med. 2001;23(2):79-87. [PubMed: 11394558]

25. Dallow $\mathrm{CB}$, Anderson J. Using self-efficacy and a transtheoretical model to develop a physical activity intervention for obese women. Am J Health Promot. 2003;17(6):373-81. [PubMed: 12858617]

26. Opdenacker J, De Bourdeaudhuij I, Auweele YV, Boen F. Psychosocial mediators of a lifestyle physical activity intervention in women. Psychol Sport Exerc. 2009;10(6):595-601. doi: 10.1016/j. psychsport.2009.03.002.

27. Shirazi KK, Wallace LM, Niknami S, Hidarnia A, Torkaman G, Gilchrist $\mathrm{M}$, et al. A home-based, transtheoretical change model designed strength training intervention to increase exercise to prevent osteoporosis in Iranian women aged 40-65 years: A randomized controlled trial. Health Educ Res. 2007;22(3):305-17. doi: 10.1093/her/cyl067. [PubMed:16928779]

28. IPAQ Guidelines for data processing and analysis of the international physical activity questionnaire (ipaq)-short form. 2014. Available from: www.ipaq.ki.se.

29. Marcus BH, Rakowski W, Rossi JS. Assessing motivational readiness and decision making for exercise. Health Psychol. 1992;11(4):257-61. [PubMed:1396494]

30. Biddle SJ, Nigg CR. Theories of exercise behaviour. Int J Sport Psy- chol .2000;31:290-304.

31. Sechrist KR, Walker S, Pender NJ. Development and psychometric evaluation of the exercise benefits/barriers scale. Res Nurs Health 1987;10(6):357-65. doi: 10.1002/nur.4770100603.

32. Nigg CR, Riebe D. The transtheoretical model: Research review of exercise behavior and older adults. Promoting exercise and behavior change in older adults: Interventions with the transtheoretical model.New York : Springer; 2002.

33. Titze S, Martin BW, Seiler R, Stronegger W, Marti B. Effects of a lifestyle physical activity intervention on stages of change and energy expenditure in sedentary employees. Psychol Sport Exerc. 2001;2(2):103-16. doi: 10.1016/s1469-0292(00)00016-9.

34. Lach HW, Everard KM, Highstein G, Brownson CA. Application of the transtheoretical model to health education for older adults. Health Promot Pract. 2004;5(1):88-93. doi: 10.1177/1524839903257305. [PubMed: 14965439]

35. Woods C, Mutrie N, Scott M. Physical activity intervention: A transtheoretical model-based intervention designed to help sedentary young adults become active. Health Educ Res. 2002;17(4):451-60. [PubMed: 12197590]

36. Kirk A, MacMillan F, Webster N. Application of the Transtheoretical model to physical activity in older adults with Type 2 diabetes and/or cardiovascular disease. Psychol Sport Exerc. 2010;11(4):3204. doi: 10.1016/j.psychsport.2010.03.001.

37. Manley D, Cowan P, Graff C, Perlow M, Rice P, Richey P, et al. Selfefficacy, physical activity, and aerobic fitness in middle school children: examination of a pedometer intervention program. J Pediatr Nurs. 2014;29(3):228-37. doi: 10.1016/j.pedn.2013.10.011. [PubMed: 24263251]

38. Nishida Y, Suzuki H, Wang DH, Kira S. Psychological determinants of physical activity in Japanese female employees. J Occup Health. 2003;45(1):15-22. [PubMed: 14605424]

39. Callaghan P, Eves FF, Norman P, Chang AM, Lung CY. Applying the Transtheoretical Model of Change to exercise in young Chinese people. Br J Health Psychol. 2002;7(Part 3):267-82. doi: 10.1348/135910702760213670. [PubMed: 12614500]

40. Nourouzi A, Ghofranipour F, Heydarnia A, Tahmasbi R. Determinants of physical activity based on Health Promotion Model (HPM) in diabetic women of Karaj diabetic institute. Iran South Med J. 2010;13(1):41-51.

41. Zeidi I, Ziaeiha M, Variani AS, Khalaj M, Zeidi B, Tonekaboni $\mathrm{H}$. Predicting the stages of change in physical activity behavior of QUMS students with Pender's model. J Qazvin Univ Med Sci. 2010;14:58-66.

42. Gorely T, Bruce D. A 6-month investigation of exercise adoption from the contemplation stage of the transtheoretical model. Psychol Sport Exerc. 2000;1(2):89-101. doi: 10.1016/s14690292(00)00012-1.

43. Kim Y, Cardinal BJ, Lee J. Understanding exercise behavior among Korean adults: A test of the transtheoretical model. Int J Behav Med. 2006;13(4):295-303. doi: 10.1207/s15327558ijbm1304_4. [PubMed:17228987]

44. Pan FC, Chen CH.Application of the transtheoretical model of exercise behavior change plan in high school students. Int J Human Soc Sci. 2010;5(10):680-5.

45. Taymoori P, Niknami S, Berry T, Lubans D, Ghofranipour F, Kazemnejad A. A school-based randomized controlled trial to improve physical activity among Iranian high school girls. IntJ Behav Nutr Phys Act. 2008;5:18. doi:10.1186/1479-5868-5-18. [PubMed: 18387174]

46. World Health Organization. Global recommendations on physical activity for health. World Health Organization. 2010. 